\title{
Long-term home oxygen: a UK perspective
}

\author{
Ian M. Balfour-Lynn*
}

There is little doubt that children with chronic hypoxemia benefit from supplemental oxygen, which, when appropriate, can be administered outside the hospital setting. Long-term home oxygen is now a well recognized form of therapy; however, as is often the case in pediatric practice, evidence for its benefit is not always convincing. This was highlighted in the 2009 British Thoracic Society (BTS) guidelines for home oxygen in children, ${ }^{1}$ in which only $15 \%$ of the recommendations were graded A, B or C. ${ }^{2}$ This fact has inevitably led to variable practice, lack of consensus, and possible misuse of supplemental oxygen. In this issue of Jornal de Pediatria, Munhoz et al. ${ }^{3}$ present a retrospective cohort study of 165 patients from a single pediatric center in São Paulo, Brazil, receiving home oxygen during the 8-year period of 2002 to 2009. Their paper reviews the underlying diagnoses of patients on home oxygen, compares those with and without secondary pulmonary hypertension, and performs a cost analysis. This editorial will give a UK perspective on these issues.

\section{Who is getting home oxygen?}

The main diagnoses in the Brazilian series were cystic fibrosis $(22 \%)$, bronchopulmonary dysplasia (19\%), bronchiolitis obliterans (15\%), and "neuropathy" (10\%). These percentages contrast quite markedly with data available for the England and Wales home oxygen service. ${ }^{4}$ The England and Wales data were obtained from a prospective analysis of home oxygen order forms for 888 children who started treatment during a 3-year period (2006-2009), and also from a cross-sectional survey of 3,338 children receiving home oxygen in June 2007 that assessed anonymized data provided by the companies delivering the oxygen.

\section{Cystic fibrosis}

The use of home oxygen for cystic fibrosis (CF) in São Paulo is markedly high compared to England and Wales and it was the commonest indication (22\% of the cases). The center was looking after 150 children with CF at the time of the study (Andréa Munhoz, personal communication), and $36(24 \%)$ were on oxygen. In the $\mathrm{UK}$, it is estimated that only $1-2 \%$ of CF children have home oxygen, ${ }^{5}$ and currently, at the Royal Brompton Hospital Pediatric CF Unit, we have only one child out of 320 who requires it. This discrepancy probably reflects a number of differences in the availability of CF services and therapies rather than inherent differences in CF severity between the continents. Such a supposition is backed up by the fact that in the CF unit in Porto Alegre, Brazil, four out of $143(3 \%)$ patients under 16 years had home oxygen, which is in line with the UK rates (Fernando Abreu e Silva, personal communication). There may have been some

* BSc. MBBS. MD. Fellow, Royal College of Physicians, London, UK. Fellow, Royal College of Paediatrics and Child Health, London, UK. Fellow, Royal College of Surgeons (FRCS), London, UK. Diploma, History of Medicine, Society of Apothecaries, London, UK. Department of Paediatric Respiratory Medicine, Royal Brompton Hospital, London, UK.

No conflicts of interest declared concerning the publication of this editorial.

The Home Oxygen Database was funded by a grant from the British Lung Foundation and Carburos Metálicos (of Air Products), but is no longer active.

Suggested citation: Balfour-Lynn IM. Long-term home oxygen: a UK perspective. J Pediatr (Rio J). 2011;87(1):1-3.

doi:10.2223/JPED.2073 
young adults with inevitably more severe disease included in the São Paulo series, as, although the study was based in a children's institute, the age range of patients included went up to 21 years.

Home oxygen is indicated for hypoxemic CF children, i.e., those with the most severe lung disease. However, unless it provides symptomatic relief, our experience shows that most children are reluctant to undergo the treatment. Evidence for benefit has been hard to obtain, and the main study (which was small and had methodological problems) demonstrated an increased school attendance but, not too surprisingly, no effect on hospitalization or mortality. ${ }^{6}$ For this reason, home oxygen is best reserved for patients who get symptomatic benefit, and should not be used automatically as a response to low oxygen saturation levels.

\section{Bronchopulmonary dysplasia}

This was the second commonest indication in São Paulo, accounting for $19 \%$ of cases. There is no surprise that it is being given to babies with chronic neonatal lung disease, as this is easily the condition with most evidence for benefit of long-term oxygen therapy. The benefits include high survival rates, possible reduction of sudden unexplained death in infancy, reduction or prevention of pulmonary hypertension, reduction of intermittent desaturations, reduction in airway resistance, improvement in neurodevelopment, and promotion of growth. ${ }^{1}$ There is also some evidence that delivering the oxygen at home is beneficial in terms of quality of life and psychological impact for the family, as well as reduction in health service costs.

The main difference from the UK is that in that country chronic neonatal lung disease is by far the commonest indication for home oxygen, accounting for $68 \%$ of cases in the prospective survey and for $44 \%$ of the cross-sectional data $^{4}$; the age distribution in England and Wales clearly reflects the fact that infants are the prime treatment recipients, ${ }^{4}$ whereas in São Paulo the median age of starting the therapy was higher, at 3.6 years. The reason for this large difference is partly due to the relatively high proportion of CF patients receiving home oxygen (although we do not have actual prevalence data on this), but it may also reflect differences in the survival of preterm babies, so that there are less survivors with severe bronchopulmonary dysplasia in Brazil going home on oxygen. It may also reflect differences in the ethos of sending small babies home on oxygen and the availability of community nursing support which is so critical for a successful outcome.

\section{Bronchiolitis obliterans}

This was also a common indication in São Paulo, accounting for $15 \%$ of cases. This percentage is much higher than one would find in the UK, where bronchiolitis obliterans is a rare disorder, indeed so uncommon that this diagnosis did not receive a clinical code within the home oxygen ordering system, so we have no actual data on its indication in the UK. The high prevalence in Brazil is explained by the fact that the disease is relatively common in the southern hemisphere, presumably following adenovirus infection, and most large case series have come from South America. ${ }^{7}$ In an earlier but smaller series of patients on home oxygen from Porto Alegre, Brazil, bronchiolitis obliterans was the commonest cause (78\% of cases), although those authors did not seem to have any children with bronchopulmonary dysplasia in their series. ${ }^{8}$ In contrast, in the UK, bronchiolitis obliterans is more commonly seen as a complication of lung transplantation.

\section{Neurodisability}

The next commonest diagnosis was "neuropathy" (15\%) but it is unclear what condition the term refers to, although I assume it refers to children with a neurodisability. The next most common indication was chronic aspiration lung disease $(10 \%)$. It is likely that some patients with this condition have dysfunctional swallowing or severe gastroesophageal reflux, so some of them may also have a neurodisability.

Surprisingly, neurodisability was the second commonest indication in England and Wales, ${ }^{4}$ something that was not anticipated before the study was completed. The reasons why so many children with neurodisability require home oxygen are still unclear, and in some cases this therapy may be inappropriate. The BTS guidelines recommend that the use of home oxygen in children with severe neurodisability and low oxygen saturations should be driven by quality of life issues rather than oxygen saturation targets. ${ }^{1}$ In addition, the use of home oxygen for children with recurrent status epilepticus is not routinely recommended. ${ }^{1}$

\section{Secondary pulmonary hypertension}

The paper also reports that $51 \%(69 / 134)$ of children had secondary pulmonary hypertension diagnosed by echocardiography, and that its presence was associated with higher oxygen flows and a longer duration of oxygen requirement. This is an association, but not necessarily a causal one, as home oxygen is more likely to be administered in the presence of secondary pulmonary hypertension. In addition, this association possibly reflects more severe lung disease in patients with secondary pulmonary hypertension. Supplemental oxygen acutely ameliorates pulmonary hypertension in infants with chronic neonatal lung disease, and right ventricular hypertrophy has been shown to resolve in infants on a home oxygen program when saturations are maintained above $94-95 \% .{ }^{9}$ The prevalence of pulmonary hypertension in this study was quite high, and it must be borne in mind that estimating mean pulmonary arterial 
pressure by echocardiography is a difficult technique and can lead to overestimation.

\section{Cost analysis}

Home oxygen is expensive, although it is still cheaper than keeping a child in hospital solely for oxygen therapy. The analysis from São Paulo is an estimate rather than formal cost analysis but did show that using oxygen cylinders was more than twice as expensive as using concentrators (200 vs. 90 thousand U.S. dollars per year for their program). Cost of electricity was not included as it is paid for by the family. In this case, UK families are reimbursed for the extra electricity used. Of course backup cylinders are necessary anyway, particularly if the electricity supply is unreliable due to intermittent power cuts. In the UK, the cost of home oxygen to the National Health Service is determined by the type (i.e., long-term vs. ambulatory, etc.) rather than by the mode of delivery (cylinder vs. concentrator), but generally concentrators are preferred unless it is likely that the child will only require low-flow oxygen for a short while. ${ }^{1}$ Children will also have a backup cylinder in case of concentrator failure, and small portable cylinders so that the child can be taken outside the home.

\section{Conclusions}

This is an interesting study but limited by being from a single center, which inevitably means that local practice in terms of referral patterns and management strongly influences the data. It would be ideal if all the tertiary centers in Brazil could get together to prospectively study this important patient group.

\section{References}

1. Balfour-Lynn IM, Field DJ, Gringras P, Hicks B, Jardine E, Jones $\mathrm{RC}$, et al; Paediatric Section of the Home Oxygen Guideline Development Group of the BTS Standards of Care Committee. BTS guidelines for home oxygen in children. Thorax. 2009;64 Suppl 2:ii1-26.

2. Scottish Intercollegiate Guidelines Network. Annex B: Key to evidence statements and grades of recommendations. http:// www.sign.ac.uk/guidelines/fulltext/50/annexb.html. Access: 21/12/2010.

3. Munhoz AS, Adde FV, Nakaie CM, Doria Filho F, Silva Filho LV, Rodrigues JC. Long-term oxygen therapy in children and adolescents: analysis of clinical use and costs of a home care program. J Pediatr (Rio J). 2011;87:13-18.

4. Primhak RA, Hicks B, Shaw NJ, Donaldson GC, Balfour-Lynn IM. Use of home oxygen for children in England and Wales. Arch Dis Child. 2010 Jun 3. [Epub ahead of print].

5. Balfour-Lynn IM, Primhak RA, Shaw BJ. Home oxygen for children: who, how and when? Thorax. 2005;60:76-81.

6. Zinman R, Corey M, Coates AL, Canny GJ, Connolly J, Levison H, Beaudry PH. Nocturnal home oxygen in the treatment of hypoxemic cystic fibrosis patients. J Pediatr. 1989;114:368-77.

7. Fischer GB, Teper A, Colom AJ. Acute viral bronchiolitis and its sequelae in developing countries. Paediatr Respir Rev. 2002;3:298-302.

8. Mocelin HT, Fischer GB, Ranzi LC, Rosa RD, Philomena MR. Oxigenoterapia domiciliar em crianças: relato de sete anos de experiência. J Pneumol. 2001;27:148-52.

9. Baraldi E, Carra S, Vencato F, Filippone M, Trevisanuto D, Milanesi $O$, et al. Home oxygen therapy in infants with bronchopulmonary dysplasia: a prospective study. Eur J Pediatr. 1997; 156:878-82.

\author{
Correspondence: \\ Ian M Balfour-Lynn \\ Royal Brompton Hospital \\ Sydney Street, SW3 6NP - London, UK \\ Tel.: +44 (0) 207.351 .8509 \\ Fax: +44 (0) 207.349.7754 \\ E-mail: i.balfourlynn@ic.ac.uk
}

